\title{
O QUE É UM TRANSECT E SUA UTILIZAÇÃO NOS ESTUDOS CLIMÁTICOS
}

\author{
WHAT IS A TRANSECT AND ITS USE IN CLIMATE STUDIES
}

\author{
Edson Soares Fialho \\ ${ }^{1}$ Universidade Federal do Espiríto Santo (UFES), Vitória, Espírito Santo, Brasil
}

Correspondência para: Edson Soares Fialho (fialho@ufv.br)

doi: 10.12957/geouerj.2019.40951

Recebido em: 15 ago. 2018 | Aceito em: 20 out. 2018

\section{RESUMO}

O que é um transect? A sua mera utilização deixa o usuário alheio ao esforço intelectual despendido por pesquisadores na construção da técnica. Desde a graduação procuramos referências sobre suas origens, porém não obtivemos. Assim, este trabalho procura fazer um apanhado histórico, dentro do âmbito da ciência, do processo de construção do transect, bem como utilizá-lo no estudo da pluviosidade na cidade do Rio de Janeiro, que tem disponibilizado os dados pluviais, via internet, pelo Sistema Alerta Rio. O nosso intuito é analisar a influência da topografia na distribuição da chuva (1997-2016) e seu impacto na população carioca, frequentemente afetada por eventos episódicos pluviais intensos, que acarretam inundações, enchentes e deslizamentos de encostas, com vítimas fatais e perdas materiais.

Palavras-chave: Transects. Impacto Pluvial. Rio de Janeiro.

\section{ABSTRACT}

What is a transect? Its mere use leaves the user oblivious to the intellectual effort expended by researchers. And since graduation we have looked for references about their origins and did not get it. This work tries to make a survey of the construction of the technique, as well as to use it in the studies of rainfall in the city of Rio de Janeiro, which has made data available on the Internet, by the Rio Alerta System, in order to analyze the influence of topography on the distribution of rainfall (1997-2016) and its impact on the Carioca population, often affected by episodic intense rainfall events, which lead to floods and landslides, with fatalities and material losses.

Keywords: Transects. Pluvial Impact. Rio de Janeiro.

\section{INTRODUÇÃO}

O interesse pelos fenômenos relacionados à atmosfera sempre fizeram parte do inconsciente imaginário do ser humano, na medida em que os ritmos de vida, desde a antiguidade, eram quase que determinados pelos eventos atmosféricos, tais como: a sazonalidade da pluviosidade, as tempestades, as ondas de calor e frio, que, dependendo de sua intensidade, poderiam limitar ou delongar as opções de ação dos seres viventes. 
No âmbito da ciência geográfica, Conti (2001, p. 92) afirma que o estudo do clima é relevante no discurso dos Geógrafos, pois a realidade geográfica ao ser construída de uma convergência racional de elementos e processos evolutivos, cada qual com sua especificidade e ritmos próprios, exige que a Geografia relacione dados heterogêneos e diacrônicos, apresentando grande variedade de métodos de pesquisa.

Nesse sentido, a evolução dos equipamentos meteorológicos, com a automação da rede meteorológica brasileira e mundial, permitiu a possibilidade de registros horários e, por conseguinte, popularizou o acesso aos dados primários. Além disso, cabe destacar os benefícios do sensoriamento remoto, bem como as técnicas geoestatísticas de representação espacial, que muito auxiliam na confecção de mapeamentos.

Segundo Ugeda Júnior; Amorim (2016, p. 170), as representações espaciais demonstraram avanços significativos na Geografia como um todo. Isso porque, a despeito das excessivas críticas recentes aos mapas isopléticos, elaborados através de interpolação de dados, como qualquer outra representação espacial, serão uma abstração da realidade e os resultados serão mais ou menos fiéis à realidade em função de fatores como: densidade da malha de registro de dados, sua distribuição espacial, a escolha das unidades geoambientais, o método utilizado para interpolar os dados, dentre outros.

Contudo, a elaboração de um mapeamento requer uma rede de monitoramento com número adequado de pontos de registros, a fim de se ter condição para o mapeamento. Caso contrário, a técnica pode criar distorções. Isso não quer dizer que ter uma rede com pouca representatividade espacial obrigue 0 pesquisador a descartar os dados, pois os mesmos podem ser utilizados por meio do Transect.

\section{TRANSECT E SEU USO PELA CIÊNCIA}

O método do Transect foi utilizado por Alexander von Humboldt durante suas viagens ao redor do mundo, quando o mesmo coletava informações, durante seus trabalhos de campo exploratórios, na passagem do século XVIII, nas Américas (1799-1804) e também no século XIX (1829), na Ásia 
Central, inserido no contexto da“globalização" realizada por meio da navegação marítima entre as metrópoles e as colônias (HEYD, 2017).

Porém, o primeiro registro de um Transect foi publicado por Giraud-Soulavie, 1784, representando a secção transversal das encostas montanhosas dos Vivaroises, através dos respectivos limites dos climas, da vegetação, da pressão atmosférica e altitude em relação ao mar Mediterrâneo (ROBIC, 2014; EGERTON, 2018).

O autor distingue quatro "climas" (estratos): os de oliveiras, vinhas, castanheiros e um clima alpino, dos quais representa os limites superiores, num perfil topográfico acompanhado pela localização simbólica de cidades e aldeias, e uma representação de formações vegetais (Figura 1).

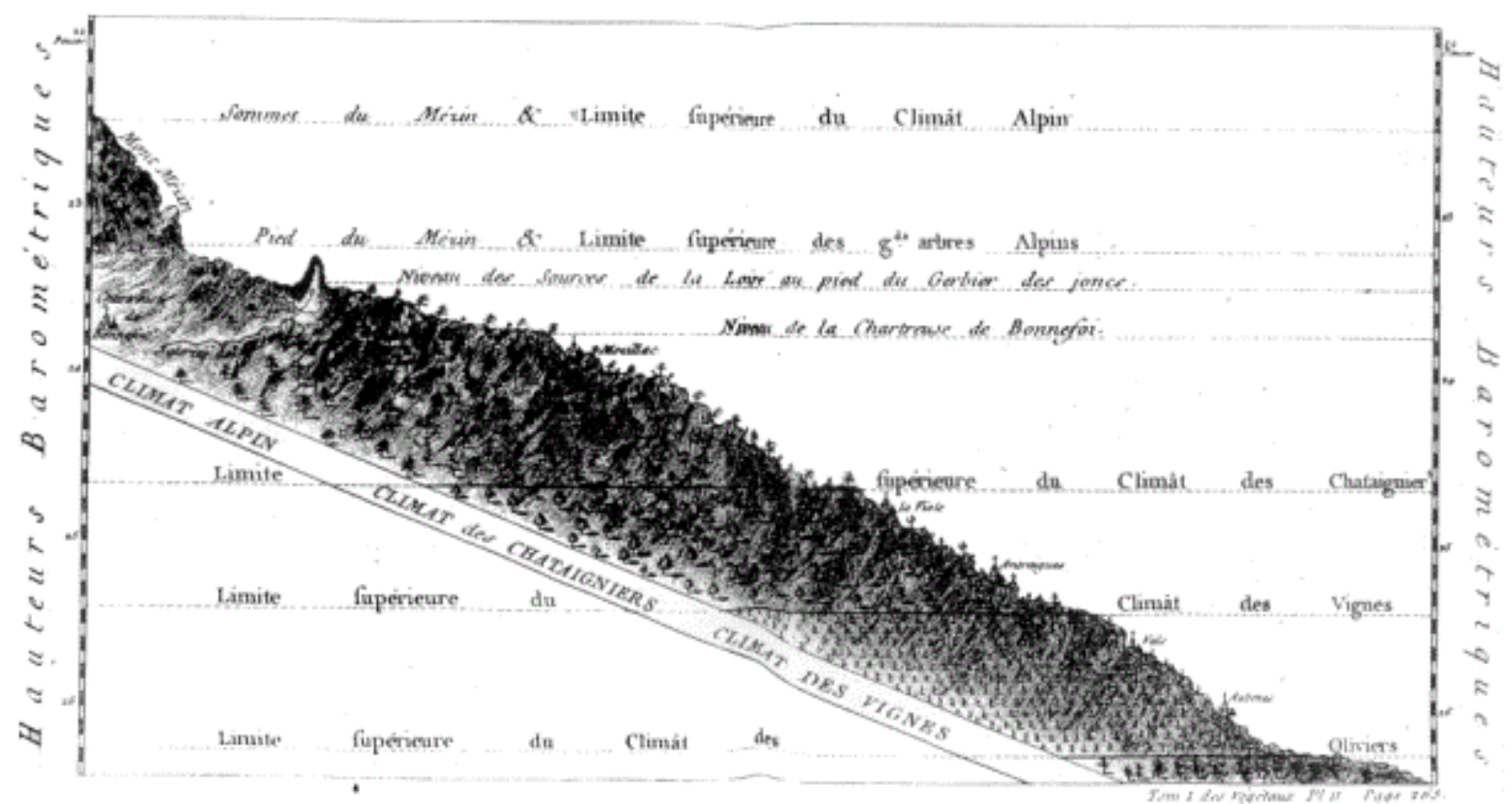

Figura1. Transect vertical da montanha de Vivaroises. Disponível em: http://medarus.org/Ardeche/07celebr/07celTex/soulavie-giraud_jean_louis.htm. Acesso em 14 jul. 2018.

Humbolt, em seu diário, descreve seu modo de trabalho, prática que lhe permitiu ser um pesquisador inovador, na medida em que ultrapassou as fronteiras da própria ciência disciplinar, conforme afirma Wulf (2016). 
Apesar da identificação da origem da utilização de um Transect, qual seria a sua definição? Segundo Pousin et al. (2016), o termo refere-se a uma transecção através da qual um objeto, ou o recorte da paisagem, observado e/ou analisado ao longo de um seguimento, linear ou não, e podendo ser empregado numa sobreposição de realce ou numa sucessão de relações espaciais simbólicas, faunísticas, florísticas entre os fenômenos.

Corroborando tal premissa, Robic (2004) expõe que o Transect (corte ou perfil) designa um dispositivo com função de observar o terreno ou de representar um espaço, ao longo de um enredo linear e de acordo com a dimensão vertical, destinado a destacar uma superposição, uma sucessão espacial ou relações entre fenômenos: seção geológica e biogeográfica. Dentre os exemplos citados por Robic (op.cit.) destacam-se:

1. Perfil topográfico, ou figura horizontal de um relevo, mostrando apenas a forma como se destaca no horizonte.

2. Perfil de um rio: longitudinal (na direção do curso de água) e transversal (perpendicular ao seu curso), perfil de equilíbrio (como escavação e assoreamento que se compensam mutuamente).

3. Perfil urbano (perfil urbano ou linha do céu): como perfil topográfico, figura horizontal formada pela linha de telhados.

4. Perfil do solo: representação gráfica da superposição de horizontes em um solo.

5. Perfil do pólen: representação figurativa da distribuição dos vários tipos de pólen em uma formação.

6. Perfil da população: também utilizado para caracterizar uma população estatística.

Na Biologia, o Transect é definido como uma faixa amostral de uma comunidade florística com comprimentos e larguras variáveis - a serem definidos de acordo com o interesse do pesquisador. 0 chamado Transect de linha (YAPP, 1956; BEENAERTS, BERGHE, 2005) é utilizado quando se deseja ilustrar um gradiente ao longo do qual comunidades de plantas e animais mudam ou caracterizam áreas ecotonais ou diferentes estágios sucessionais (BROWER; ZAR, 1984).

Os Transects fornecem uma maneira de visualizar as mudanças que ocorrem ao longo da linha e são úteis apenas em distâncias relativamente curtas, pois apenas registram o que contém no lugar amostral, provendo informações limitadas sobre a quantificação de espécies presentes. Por isso, podem ser realizados com bastante agilidade para fins de inventário ou monitoramento de pequenas áreas. Quando são mais demorados elimina grande parte do viés decorrente do ritmo subjetivo, além de não 
produzirem tanta informação sobre as densidades relativas de espécies individuais como faria um transect de cinturão (BUCKLAND; TURNOCK, 1992)ํ․․

Na Arquitetura, o Transect é um dispositivo para observar o terreno ou a representação de um espaço, ao longo de um percurso linear (uma seção transversal geográfica) destinado a revelar uma seqüência de ambientes ou uma superposição, ou sucessão espacial, e suas relações entre fenômenos em torno de uma rota pela intenção de ter um documento síntese (TIXIER, 2016).

Para os ambientes ocupados pelos seres humanos, esta seção transversal pode ser usada para identificar um conjunto de habitats que variam de acordo com seu nível e intensidade do caráter urbano - um continuum que varia de rural a urbano, o que difere essa técnica em alguns aspectos da abordagem cartográfica. Segundo Cambrezy; Maximy (1995), esse modo de representação elimina o mapa $^{2}$, uma criação de base euclidiana do espaço que, segundo Fonseca (2007), estaria em crise, pois para a expressão dos fenômenos a serem representados hoje ele é insuficiente, visto que sua essência seria por natureza antissocial e ultrapassada.

Com base nessa nova apropriação pela arquitetura, o Transect alçou um novo patamar, se transformou em uma ferramenta de produção de conhecimento e análise da paisagem. Hoje ele é reivindicado como tal no campo do planejamento urbano, com uma perspectiva interdisciplinar, onde a paisagem é o elemento agregador do diálogo que busca descrever as qualidades relacionais e dinâmicas atmosféricas dos sítios, assim como atingir o real objetivo de uma arquitetura paisagística que é melhorar a compreensão do designer sobre paisagens através do cultivo do espaço aberto ao lado de um diálogo franco com a presença e complexidades das características culturais e naturais dos lugares (DIEDRICH et al., 2014).

\footnotetext{
${ }^{1}$ Com largura de 2 a 5 metros ao longo do segmento.

${ }^{2}$ A compreensão de um território pelo transect difere, em certos aspectos, das abordagens cartográficas atualmente desenvolvidas dentro das análises da paisagem. De fato, esse modo de representação possibilita superar tanto a representação superficial do espaço quanto as funções retóricas de argumentação e crença que estão no mapa (CAMBREZY; MAXIMY, 1995).
} 
Os designers, muitas vezes, não possuem ferramentas de representação e mapeamento capazes de capturar e expressar qualidades efêmeras. Essas qualidades abstratas, que existem sobre as condições físicas do local, correspondem aos campos das ciências naturais e da estética espacial.

Daí o Transect, inspirado no método de viagem transreal (BRAAE et al., 2013) e coleta transversal de informações efêmeras de Alexander von Humboldt, amplia a perspectiva do trabalho de campo exploratório, que se utiliza de três ferramentas bem conhecidas: o esboço, a foto e o modelo em resposta às condições do local que se encontram ao longo da jornada (POUSIN, 2016) e que também contribuem para a renovação de modos de representação e para a multiplicação de abordagens experimentais que visam colocar a paisagem em debate.

Cabe destacar que outras áreas do saber também utilizam esse procedimento, tais como: Pelologia (CHIG et al., 2008; DIAS et al., 2003); Hidrologia (PALMA et al., 2009); Geologia (SANTOS et al., 2013); Arqueologia (CALDARELLI, 1999); Engenharia Florestal (CARDOSO et al., 2013), Urbanismo (JOURET, 1972) e Climatologia urbana (MONTEIRO, 1990; ROCHA; FIALHO, 2010). E na Geogafia? Como esse método seria utilizado?

Segundo Robic (2004, p. 37), o Transect para os Geógrafos é um dispositivo de observação terrestre ou a representação de um espaço que demonstra uma sucessão espacial entre fenômenos, que, segundo Tixier (2017), desperta um tipo de raciocínio abdutivo, que não resulta em verdades absolutas, mas busca novas ideias e conhecimentos que possam validar algo.

Ele não prova que algo é de algum jeito, apenas diz que é mais provável que seja e busca a melhor explicação para isso. Sendo assim, é um procedimento racional de aquisição do conhecimento enquanto o raciocínio indutivo e o dedutivo servem para verificar ou comprovar a verdade de um conhecimento já adquirido.

\section{O TRANSECT NA GEOGRAFIA E NA CLIMATOLOGIA}


A questão ambiental no atual contexto mundial ganha ainda maior relevância em função dos problemas socioambientais, que não se restringem apenas às grandes cidades, mas a todos os ambientes, onde não apenas os recursos naturais são poluídos, mas também os sociais e econômicos são atingidos, afetando, por conseguinte, a qualidade de vida dos cidadãos no espaço geográfico através da paisagem.

Nesse contexto, a visão sistêmica é um importante acontecimento para a Geografia (TROPPMAIR, 2006, p. 79), pois consentiu a sistematização e, consequentemente, a integração dos elementos da natureza, suas conexões e processos como um potencial a ser utilizado pelo homem e que adquire uma importância crescente.

Porém, conforme Cavalcanti (2013), não se pode esquecer que sem os esforços de naturalistas com visão integrada do mundo, como Humboldt, as variações da latitude e da altitude passam a ser tratadas como determinantes gerais de padrões regionais e globais de ambientes naturais, passando a ser possível falar de uma teoria das zonas naturais, que viriam a sustentar as propostas posteriores desenvolvidas como os conceitos de biomas (WALTER, 1986) e geossistemas (SOCHAVA, 1977).

A abordagem na proposição geossistêmica faz-se a partir da análise integrada do complexo físicogeográfico com os componentes do meio social e econômico, sendo os estudos das relações homemnatureza e as avaliações relacionadas à qualidade ambiental, assim como sua aplicabilidade no planejamento, relevantes premissas teóricas evidenciadas pelo estudo de Sochava (1977).

No Brasil, segundo Cunha; Freitas (2004) e Ferreira (2010, p. 198), dentre os Geógrafos brasileiros que demonstraram interesse na abordagem geossistêmica percebida como uma alternativa a ser aprimorada, visando interpretação ambiental integrada, pode-se citar o professor Carlos Augusto de Figueiredo Monteiro.

De acordo com Monteiro (1996), o Geossistema, paradigma da Geografia Física, não visa somente aproximar as distintas esferas do "natural", mas sim ao entrosamento entre os fatores naturais e os fatores sociais. Além disso, Monteiro (2000) destaca que, na obra de Sochava (1977), a grande contribuição foi a implementação de técnicas de modelização convergentes que levaram à caracterização dos "regimes" dos geossistemas, fator de importância capital para o reconhecimento da 
dinâmica processual das unidades geoambientais, enfatizando o "ritmo" e a "dinâmica temporal" sobre o espaço.

Porém, Monteiro (2001) reconhece as dificuldades acerca do estabelecimento de uma ordem de grandeza espacial e do entendimento da dinâmica interna das unidades geossistêmicas devido ao envolvimento de correlações complexas advindas da incorporação das alusões socioeconômicas.

Apesar dos empecilhos, Monteiro (1978) procura elaborar um modelo incorporando a temporalidade, mas adverte sobre o uso múltiplo de peculiaridades geográficas, como: tamanho, grau de desenvolvimento econômico, capacidade científica e tecnológica das regiões. Os seguintes requisitos à modelização, então, são:

1. Montagem do modelo sob perspectiva de um sistema singular complexo onde os elementos socioeconômicos não sejam vistos como outro sistema, oponente e antagônico, mas sim incluído no próprio sistema.

2. Representação de uma realidade espacial que assume um jogo de relações sincrônicas.

3. Representação de uma inteireza diacrônica.

4. Simultaneidade e intimidade de correlação na análise temporal.

5. Necessidade de base de observação empírica e a proposição de modelos a posteriori.

6. Conjunção de análises qualitativas às análises quantitativas (MONTEIRO, 1978, p.56-59).

A partir desse ponto de vista, Monteiro $(1978 ; 2000)$ desenvolveu um modelo geossistêmico-espaçotemporal para estudos climáticos integrados às perspectivas geoecológicas e geoeconômicas, voltado para as escalas inferiores de organização espacial integrada aos sistemas naturais e incorporando as derivações das ações humanas, a partir da inclusão do tempo.

Para isso, desenvolveu perfis verticais (Transects) objetivando a percepção da dinâmica funcional interna dos elementos móveis que revelam a dinâmica temporal e que, em sequências dos elementos, revelam a dinâmica processual geossistêmica, como Monteiro (1996) destaca na Figura 2.

Monteiro (2000) ainda aponta três discussões fundamentais em aberto. A primeira considera o problema de integração "antrópica" nos geossistemas, que deve ser em função de variantes importantes, como: 
(1) a extensão do território focalizado, que conduz a escolha da escala de abordagem (configuração espacial);

(2) a duração histórica da ocupação humana e sua importância processual no jogo de relações do geossistema (configuração temporal);

(3) o grau de intensidade sob o qual se manifestam as ações antropogênicas em suas relações com as diferentes partes em que se subdividem os geossistemas.

Esses aspectos são susceptíveis de apresentar diferentes arranjos e combinações entre eles, configurando o trinômio "População - Produção - Natureza".

A partir da identificação do uso dos Transects nos estudos da paisagem, os estudos de climatologia geográfica são impregnados pela visão geossistêmica.

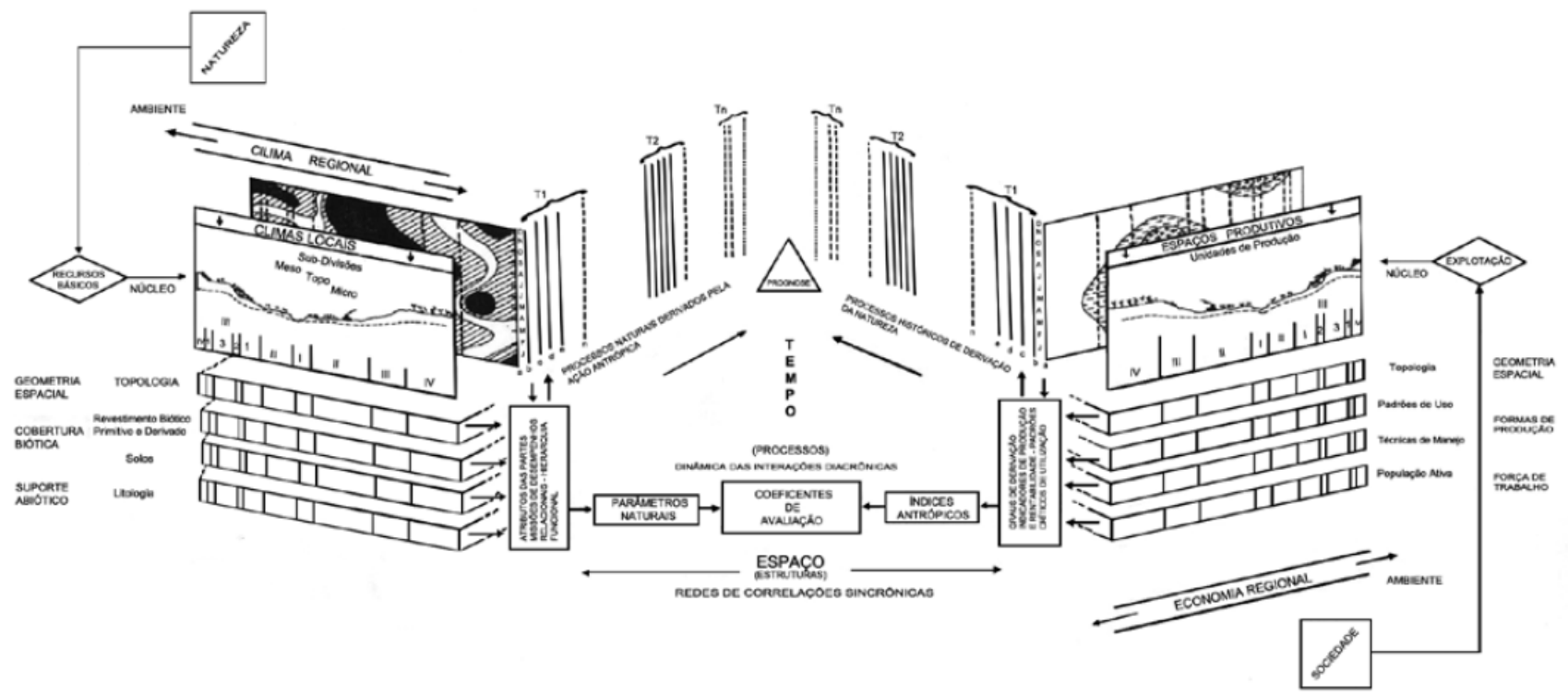

Figura 2. Desenho experimental proposto por Monteiro (1996, p. 80) na tentativa de modelização dos sistemas ambientais integrados.

Zavatini (2000, p. 32) corrobora tal visão quando afirma que: “(...) a climatologia geográfica, ao objetivar análises dos ritmos do tempo sobre o espaço, estabelece uma relação dialética entre o clima e a sociedade". Da mesma forma, de acordo com Ely (2006, p. 166), o clima, enquanto um fenômeno que regula o sistema natural, aberto às entradas de energia provindas das ações humanas, produz a estrutura espacial. Nesse sentido, a climatologia geográfica dá suporte para análise dos fenômenos 
climáticos. O clima, então, aparece como imprescindível para o desenvolvimento e a organização espacial.

Diante disso, pode-se dizer que a climatologia geográfica é uma forma de análise pautada na abordagem geossitêmica do clima (BELIZÁRIO, 2014). O clima deve ser analisado tendo como princípio a abordagem geossistêmica, pois nela considera-se, na essência, a relação entre os fenômenos físicos e sociais. Nesse sentido, o primeiro estudo de climatologia urbana a utilizar a técnica do Transect (Figura 3) foi o trabalho desenvolvido por Monteiro $(1990)^{3}$

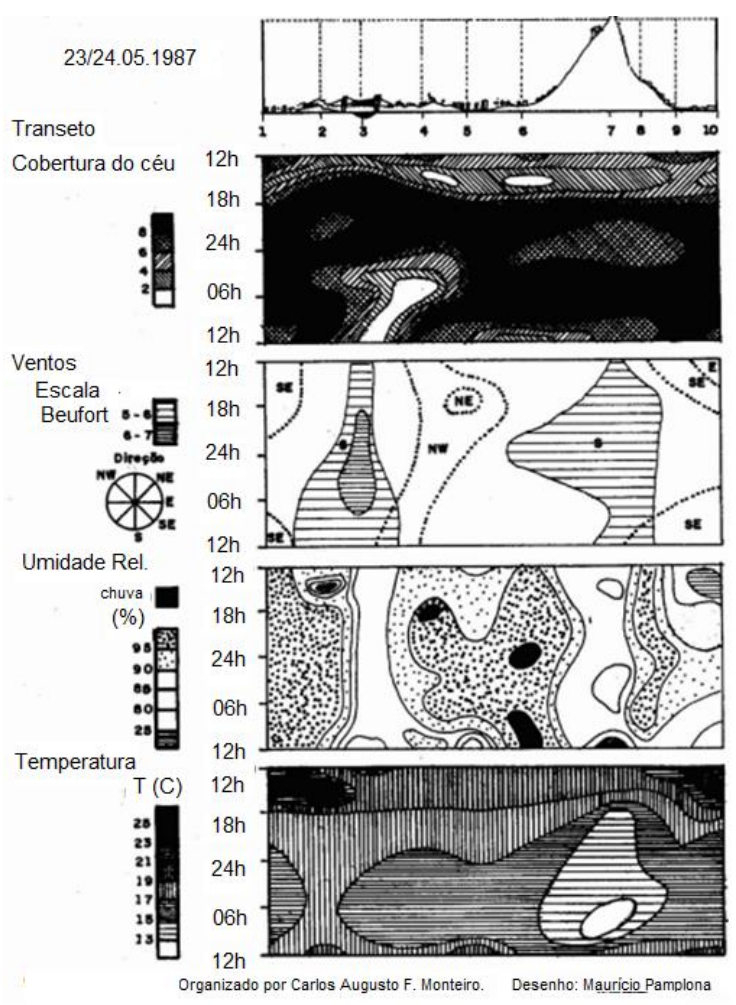

Figura 3. Variação de alguns elementos climáticos em 24 horas, na cidade de Florianópolis-SC. Fonte: Monteiro (1990, p. $34)$.

\section{APRESENTANDO UMA CIDADE... EM SUA RELAÇÃO CONFLITUOSA}

O processo histórico de ocupação do espaço urbano carioca provocou sérios problemas que resultaram num quadro ambiental crítico. A ocupação acelerada e desordenada da cidade foi responsável pelo

\footnotetext{
${ }^{3}$ Adentrar a cidade para tomar-lhe a temperatura, onde elabora um perfil da ilha de Florianópolis ao continente e subdivide a mesma em área central e o CBD (Central Bussiness District).
} 
desmatamento da Mata Atlântica e pelo surgimento de favelas nas encostas, sendo o Maciço da Tijuca o mais ocupado, mais na vertente Norte do que na vertente Sul, em virtude da maior declividade.

O sítio urbano da cidade do Rio de Janeiro apresenta grandes contrastes resultantes do relevo acidentado e responsáveis pela fragmentação da cidade e pela individualização dos bairros, além de terem influenciado no direcionamento das vias de circulação, que orientaram a expansão da cidade (ABREU, 1992).

Galvão (1992) destaca que as chuvas de verão sintetizam com clareza a questão ambiental na cidade do Rio de Janeiro, embora a distribuição sazonal das chuvas e a ocorrência de precipitações de grande intensidade nessa época seja uma característica do clima tropical úmido, onde a cidade se situa.

Os grandes impactos socioeconômicos sofridos pela cidade nos dias de episódios pluviais concentrados são provenientes da associação entre os fatores naturais e humanos, que, segundo levantamento histórico realizado por Brandão (1997), não são recentes e muito menos exclusivos do século atual. Dentre estes podem ser citados os anos de 1862, 1883, 1897 como representativos do século XIX.

As fortes chuvas nos meses de verão são quase sempre associadas à ocorrência de escorregamento nas vertentes dos maciços e enchentes nas baixadas. Os eventos episódicos concentrados de chuva e seus respectivos impactos passaram a influir na vida do carioca, principalmente, a partir dos temporais de 1966 e 1988.

A situação de tempo predominante na cidade do Rio de Janeiro é determinada pela influência do Anticiclone Subtropical do Atlântico Sul (ASAS), responsável pelas condições de céu "aberto", com ventos de fraca intensidade, possuindo a direção nordeste, atuando predominantemente no Estado (FIALHO, 1998).

Porém, existem outros sistemas transientes, como os sistemas frontais, ciclones extratropicais, sistemas convectivos de mesoescala, entre outros, que interrompem a estabilidade do tempo no Estado, aumentando a nebulosidade, o índice pluviométrico e intensificação dos ventos. Entre os meses de novembro a março é comum a atuação da Zona de Convergência Subtropical (ZCAS), que se caracteriza como uma banda de nebulosidade convectiva que se estende, em geral, desde a Amazônia até o Oceano Atlântico, numa direção noroeste-sudeste (NIMER, 1989). 
A trajetória dos sistemas frontais sobre a América do Sul segue dois padrões diferentes durante o ano. No verão a trajetória é mais lenta e caracterizada por maior atividade convectiva devido a complexas interações entre sistemas, como a ZCAS e a Alta da Bolívia. No inverno as frentes deslocam-se rapidamente, em trajetórias mais zonais, e não conseguem penetrar no interior do continente. Tais sistemas não geram grandes quantidades de chuvas no Brasil e no Sudeste brasileiro, mas, em algumas ocasiões, provocam queda da temperatura do ar em tais regiões (DERECZYNSKI et al., 2009).

\section{A INFLUÊNCIA DO SÍTIO}

A dinâmica do modo de apropriação de sítio desfavorável à ocupação, como a cidade do Rio de Janeiro, que se expandiu graças a sucessivos desmontes de morros e aterros, mostra que a natureza da cidade, portanto, não é apenas um "cenário natural" que serviu de suporte ao desenvolvimento urbano, mas que constitui um elemento urbano em si mesmo, com o qual foi necessário compor e teve que, muitas vezes, "dominar" (até mesmo destruir) para atender às necessidades da expansão urbana.

A cidade do Rio de Janeiro, então marcada pela presença da natureza (Maciços e Florestas e Lagoas) e a urbanização que parece casar com o local, não é uma cidade comum, conforme escreve Lévi-Strauss (1988, p. 89). A história da sua evolução urbana é a da formação de dois opostos, mas complementares, que, segundo Bruno (2008),“(...) de um lado, a casa grande, a cidade dos mestres... e do outro, os mucambos, ocas e senzalas, agora favelas e periferias, a cidade dos pobres, muitas vezes negros e mestiços, descendentes de escravos e populações ameríndias (...)”.

Hoje a divisão social e funcional do espaço urbano continua sendo uma das características marcantes da aglomeração carioca. A cidade revela, através da divisão de seu espaço, a estrutura da sociedade onde os ricos e os pobres vivem lado a lado perpetuando seus papéis de "senhores e servos".

Segundo Bruno (2008), no coração da cidade, os Maciços da Tijuca e Pedra Branca funcionam como um divisor de espaço, definindo dois territórios socioeconômicos diferentes: a zona sul, com os ricos distritos da orla, mar e interior; industrial e popular, norte e oeste. Esse primeiro esquema centro- 
periferia, utilizado até a década de 1970 para interpretar a estrutura socioespacial da aglomeração, evoluiu para um sistema de núcleos e periferias (VETTER, 1981).

A fratura socioespacial encontrada na escala de aglomeração é reproduzida no entrelaçamento dos bairros ricos e das favelas nas montanhas da zona sul. Apesar de sua beleza, o cenário natural do Rio constitui um obstáculo físico à urbanização que favorece a segregação e reforça o particionamento socioespacial (Figura 4).

Além da condição social, a pluviosidade também é influenciada pela disposição dos Maciços litorâneos. Os trabalhos desenvolvidos por Fialho; Brandão (1997 e 2000) abordaram a distribuição da pluviosidade e seus impactos na cidade do Rio de Janeiro, por meio da técnica de Transect, para o período de 1990 a 1996. Basearam-se nos dados pluviométricos, ao nível diário e mensal, do Ministério da Aeronáutica (MA), da SERLA (Superintendência Estadual de Rios e Lagoas) e da UERJ (Universidade do Estado do Rio de Janeiro), a fim de obter, a partir da sua distribuição e frequência, as correlações com os impactos socioeconômicos causados pelas chuvas.

A opção pela técnica decorreu da dificuldade de espacialização da pluviosidade pelos motivos expostos e reforçados pela complexidade do sítio da cidade. Considerando os aspectos geoecológicos e os componentes antrópicos, foram selecionadas 12 estações distribuídas em 2 Transetcs, partindo do centro da cidade, orientadas no sentido da expansão urbana (L-W) e acompanhando as vertentes norte e sul dos maciços montanhosos (Figura 5).

O Transect I acompanha a vertente norte e utilizou-se das estações do Aeroporto Santos Dumont (MA), Maracanã (UERJ), Benfica (SERLA), Irajá (SERLA), Campos dos Afonsos (MA), Realengo (SERLA), Campo Grande (SERLA) e Santa Cruz (MA). O Transect II segue o trajeto pelo litoral, saindo da estação Aeroporto Santo Dumont (MA) até o Aeroporto de Jacarepaguá (MA), passando pelas estações do Jardim Botânico (UERJ), Capela Mayrink (SERLA) e Via 11 (SERLA). 


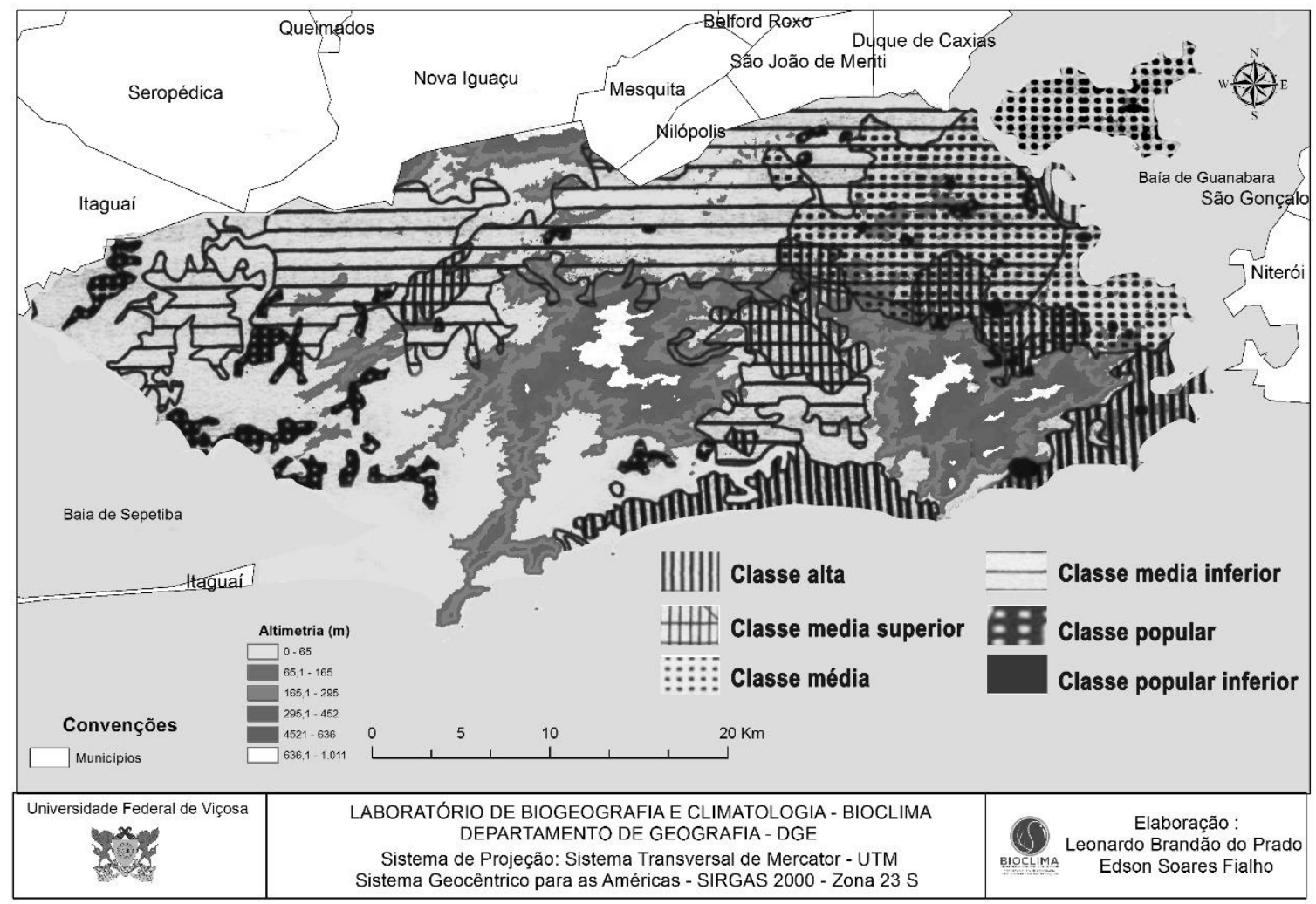

Figura 4. Distribuição das classes sociais, na cidade do Rio de Janeiro em 1996. Elaboração: Bruno (2008, p. 5). Adaptado.

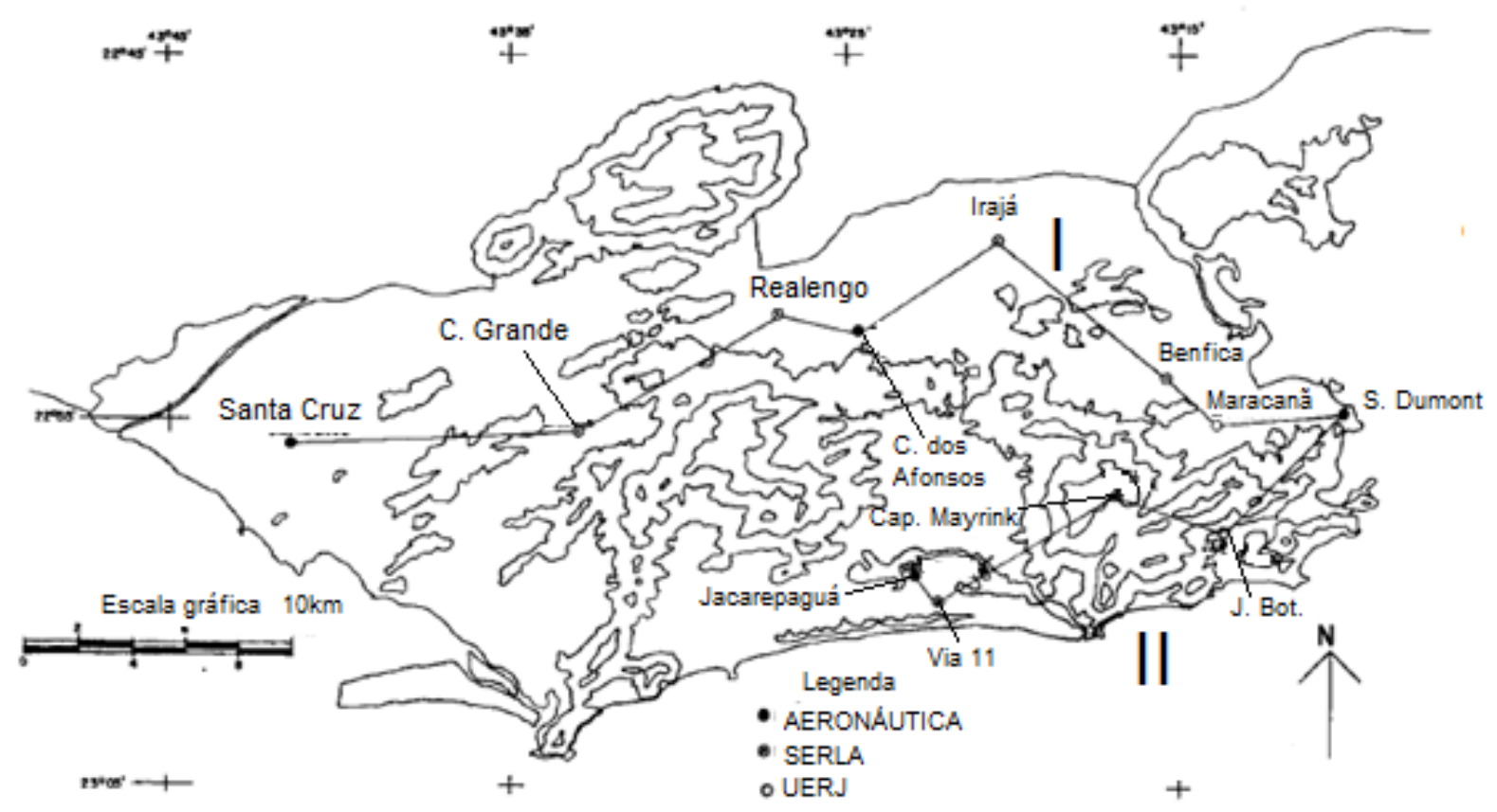

Figura 5. Estações meteorológicas e pluviométricas na cidade do Rio de Janeiro. Elaboração: Fialho (1998, p. 12). 
No transect I (Figura 6) nota-se uma grande variabilidade, quanto ao comportamento da pluviosidade, num curto espaço. Iniciando na estação Santos Dumont, percebe-se que a pluviosidade tende a diminuir em direção às estações Maracanã, Benfica e Irajá, encontrando valores mínimos na estação Realengo e, a partir daí, aumentando em direção às estações Campo Grande e Santa Cruz.

Ao observar o relevo associado à localização das estações meteorológicas e pluviométricas, vê-se que os Maciços da Tijuca e da Pedra-Branca interceptam grande parte da umidade, que se deposita na vertente sul, enquanto a norte, a sotavento, dos Maciços, onde se situam as estações do Maracanã, Benfica e Irajá, é mais seca.

A estação Realengo, com os menores índices totais pluviométricos, localiza-se a sotavento do Maciço da Pedra Branca. Esse comportamento é explicado pelo efeito Foenhn que, durante a ascendência do ar, na vertente sul (barlavento), ocorre um resfriamento adiabático e provoca o aumento da umidade pela condensação do vapor de água, bem como pelo aumento da nebulosidade.

Continuando em direção a Santa Cruz, detecta-se um incremento da pluviosidade nas estações de Campo Grande e Santa Cruz, decorrente da presença da Serra da Paciência, bem como, o fato de essas se localizarem no extremo oeste do município, sendo as primeiras a serem atingidas pela entrada dos sistemas frontais.

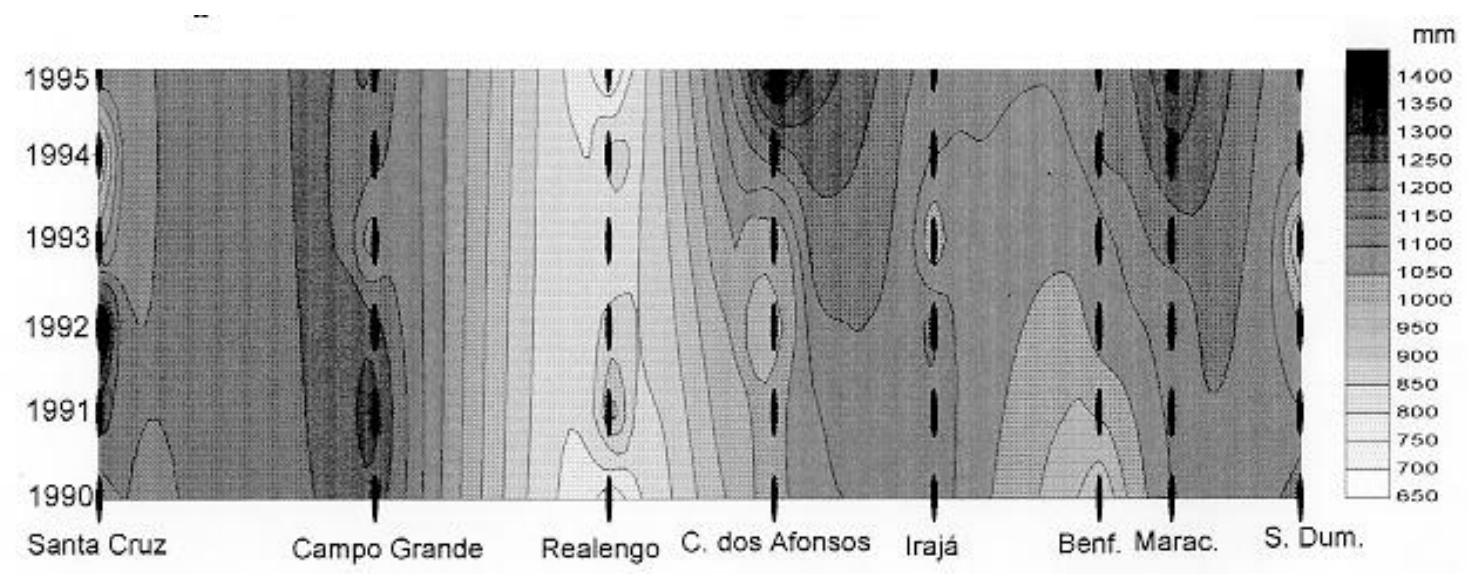

Figura 6. Variação Têmporo-espacial da Pluviosidade ao longo do Transect Santos Dumont-Santa Cruz. Elaboração: Fialho; Brandão (1997). 
No Transect II (Figura 7), ao se comparar os totais da estação Santos Dumont e Jardim Botânico em relação à Via 11 e Jacarepaguá, verifica-se que os totais pluviais anuais são superiores nas duas primeiras.

Tal fato explica-se em virtude da localização geográfica, pois estão situadas próximo ao litoral (Baía da Guanabara - S. Dumont) e próximo ao sopé de encostas abruptas, que se interpõem à penetração dos ventos úmidos do litoral, e isso propicia um acúmulo de umidade (Jardim Botânico). Capela Mayrink, por estar no alto do Maciço da Tijuca, apresenta os maiores totais, em relação aos demais postos.

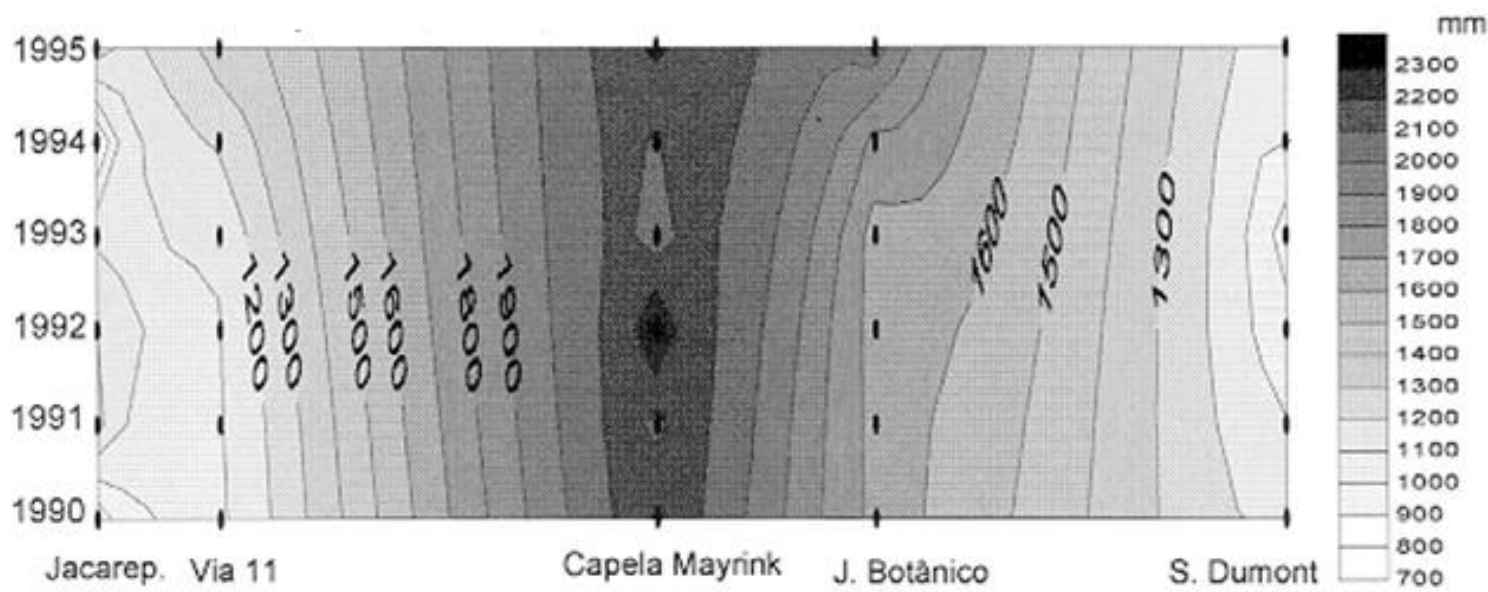

Figura 7. Variação Têmporo-espacial da Pluviosidade ao longo do Transect Santos Dumont-Santa Cruz. Elaboração: Fialho; Brandão (1997).

A comparação entre os dois Transects quanto aos totais pluviométricos anuais permite constatar que a pluviosidade no Transect II foi cerca de $25 \%$ maior que a registrada no Transect I, entretanto a análise têmporo-espacial revelou significativas variações, principalmente, em relação à sua intensidade. Esta constatação é corroborada por Davegna; Fialho (2002) quando analisaram as repercussões socioambientais decorrentes dos eventos pluviais extremos ocorridos entre 1997 e 2001, na microbacia de São Conrado, constatando a influência da topografia como regulador da distribuição das chuvas na cidade do Rio de Janeiro.

Após a apresentação dos trabalhos sobre a distribuição das chuvas na cidade do Rio de Janeiro entre 1990 e 1996, o Instituto de Geotécnica do Município do Rio de Janeiro, atual Fundação GEO-RIO, foi criado em 12 de maio de 1966, em função das chuvas ocorridas em janeiro do ano corrente que 
ocasionaram 70 mortos e mais de 500 pessoas feridas e tinha por objetivo atender a demanda ocasionada pelas fortes chuvas (AMORIM et al., 2014).

Um ano após as fortes chuvas de 1996, mais um episódio significativo depois de 30 anos, vários pontos de escorregamentos ocorreram em diversos trechos dos Maciços da Tijuca e da Pedra Branca, destruindo centenas de casa e ceifando 52 pessoas, então a GEO-RIO inaugurou no ano de 1997 um sistema de alerta de chuvas intensas e de deslizamentos em encostas, conhecido como Sistema Alerta Rio, com uma rede de 30 estações pluviométricas (BRANDAO, 2001, p. 91).

Esses dois episódios, 1966 e 1996, corroboram que, no mundo tropical, as chuvas (ou a sua ausência) assumem papel de protagonista como agente impactante na integridade do sistema urbano. Segundo Sant'anna Neto (2011, p. 54), historicamente as cidades do centro-sul do Brasil recebem precipitações da ordem de 1200 a $1800 \mathrm{~mm}$ anuais, onde cerca de $70 \%$ deste total ocorrem no período de primavera/verão.

Com base nos dados entre 1997 e 2016, o presente artigo procurou verificar, por meio da técnica de Transect, a distribuição da chuva com base nos dados de uma rede de 33 pluviômetros, dos quais foram selecionados 22 postos distribuídos a Barlavento (8 pontos - litoral); a Sotavento (8 pontos interior) e no Maciço (6 pontos - Tijuca), conforme pode ser visto na Figura 8.

A análise dos dados indica que o ano de 2014 foi o mais seco do período, com $32 \%$ abaixo da média do período. Em contrapartida, o ano de 2010 foi o mais chuvoso do período, com $25 \%$ de chuva acima da média do período.

Outro fato que corrobora Fialho; Brandão (2000) é o fato de as estações situadas próximo à Baía de Seropédica apresentarem um aumento da chuva com relação às estações situadas a sotavento do Maciço da Pedra Branca (Figura 9).

Essa localidade, segundo Oliveira Junior et al. (2013), tem direções de vento predominantes de Sudoeste (SW) e Sul-Sudoeste (SSW) que correspondem à atuação dos sistemas de brisas (brisa marítima-terrestre) na região, principalmente da brisa da Baía de Sepetiba, juntamente com a passagem de Sistema Frontal na região, enquanto as direções Norte (N) e Norte-Noroeste (NNW) 
correspondem à influência do regime de vento (brisa de vale-montanha) proveniente das cadeias montanhosas que circundam a região.

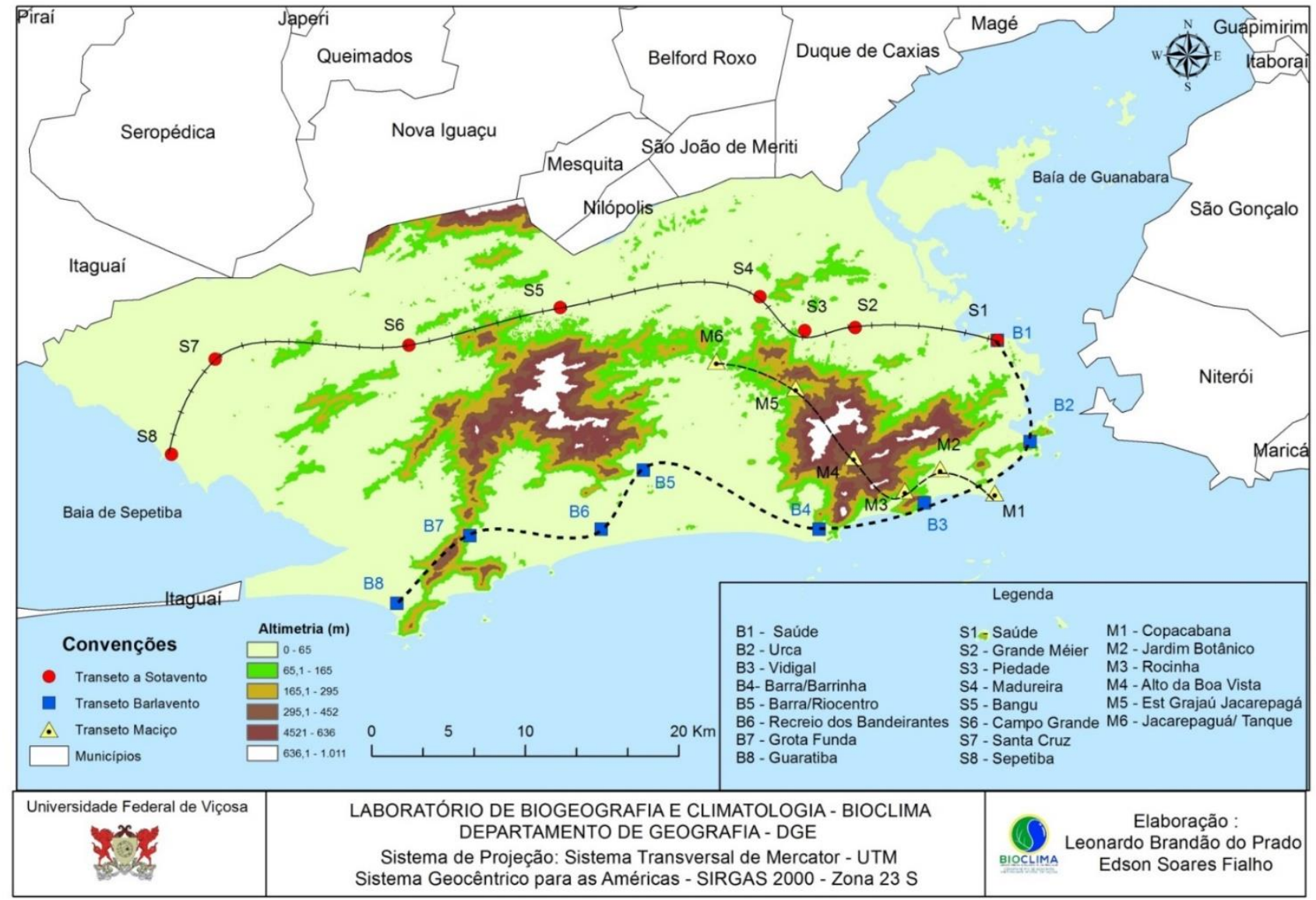

Figura 8. Localização das estações pluviométricas da GEO-RIO, na cidade do Rio de Janeiro. Elaborado por: Edson Soares Fialho e Leonardo Brandão do Prado.

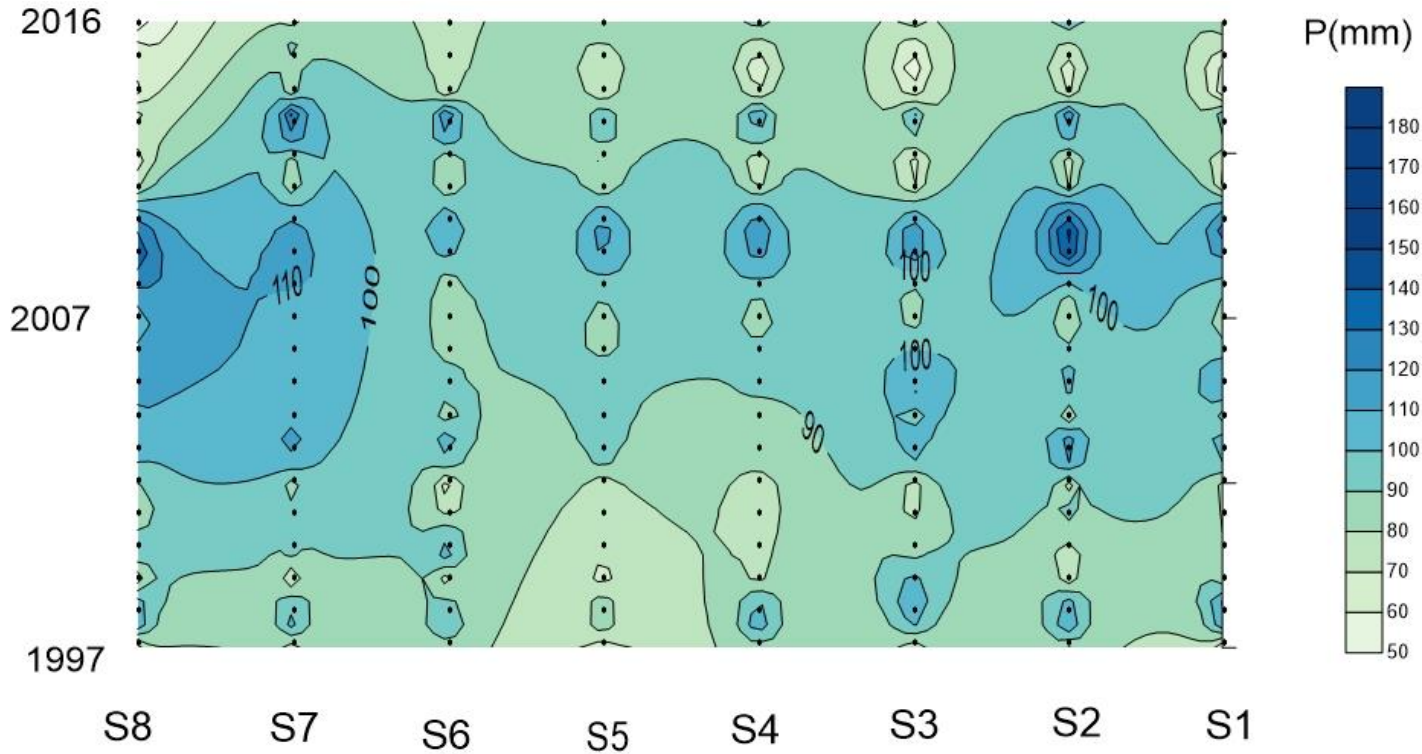

Figura 9. Variação Têmporo-espacial da Pluviosidade -Transect Saúde-Sepetiba. Fonte: Sistema Alerta Rio.Elaborado por Edson Soares Fialho e Leonardo Brandão do Prado. 
Os pontos Campo Grande e Bangu destacam-se pela ocorrência de um número elevado de percentuais de calmaria, constatado por Pimentel et. al. (2014), identificado a partir da estação meteorológica da Aeronáutica Campos dos Afonsos, que caracteriza a região como de estagnação de ventos, influenciada pelas feições topográficas locais, no caso, por estar a sotavento do Maciço da Pedra Branca, obstáculo natural às brisas marinhas, conforme pode ser visto na Tabela 1, principalmente de madrugada com 46\% de calmaria, mas também se destaca ao longo do dia em relação às demais estações.

\begin{tabular}{lccccc}
\hline \multicolumn{1}{c}{ Estação } & \% Total & \% Tarde & \% Noite & \% Madrugada & \% Manhã \\
\hline SBSC & 12 & 2 & 15 & 22 & 8 \\
Ecologia agrícola & 13 & 5 & 17 & 21 & 10 \\
SBJR & - & 2 & - & - & 15 \\
Jacarepaguá & 1 & 0 & 1 & 1 & 1 \\
SBAF & 25 & 4 & 20 & 76 & 30 \\
SBRJ & 4 & 1 & 3 & 7 & 4 \\
Centro & 3 & 1 & 4 & 1 & 11 \\
SBGL & 8 & 1 & 4 & 7 & \\
\hline
\end{tabular}

SBSC - Estação Santa Cruz; SBJR - Estação Jacarepaguá; SBAF - Estação Campo dos Afonsos; SBRJ - Estação Santos Dumont e SBGL - Estação Galeão.

Tabela 1. Percentual de calmaria nas estações de superfície em relação ao total dos dados, considerando separadamente os períodos da tarde, noite, madrugada e manhã. Fonte: Pimentel et al. (2014, p. 129).

Por outro lado, Jacarepaguá, situado no aeródromo, praticamente não registra ocorrência de ventos, tendo um padrão de direção sul à tarde e norte durante a manhã, com valores máximos de 13 nós. Os ventos, por sua vez, ao encontrarem os Maciços, são obrigados a entrarem em um processo de ascensão forçada, causando a deposição de umidade, como se observa nos pontos B4 (Rocinha-Barrinha) e B7 (Guaratiba), situados no sopé dos Maciços da Tijuca e Pedra Branca (Figura 10).

Já em relação ao Transect Maciço, a estação da Rocinha registrou o maior total pluviométrico anual e junto com a estação Medanha e Alto da Boa Vista foram as únicas a registrar um total pluvial anual superior a100mm. Essa constatação atesta que nos anos secos, nas estações situadas em altitude ou no sopé de encostas, a topografia exerce uma maior influência na definição dos locais mais chuvosos.

A análise dos dados possibilitou verificar que as estações situadas no litoral apresentaram totais pluviométricos anuais superiores, cerca de $12 \%$, em relação a sotavento. Por sua vez, o transect do Maciço apresentou totais superiores a barlavento e sotavento em $7 \%$ e 18\% respectivamente. Em termos de repercussão espacial, os bairros mais afetados ficam nos sopés das encostas e fundos de vale 
(Figura 11), configurando um efeito orográfico sobre a distribuição das chuvas, conforme verificado por Meharzi (1994), Milanesi (2007); Candido; Nunes (2008) e Forgiarini et al. (2014).

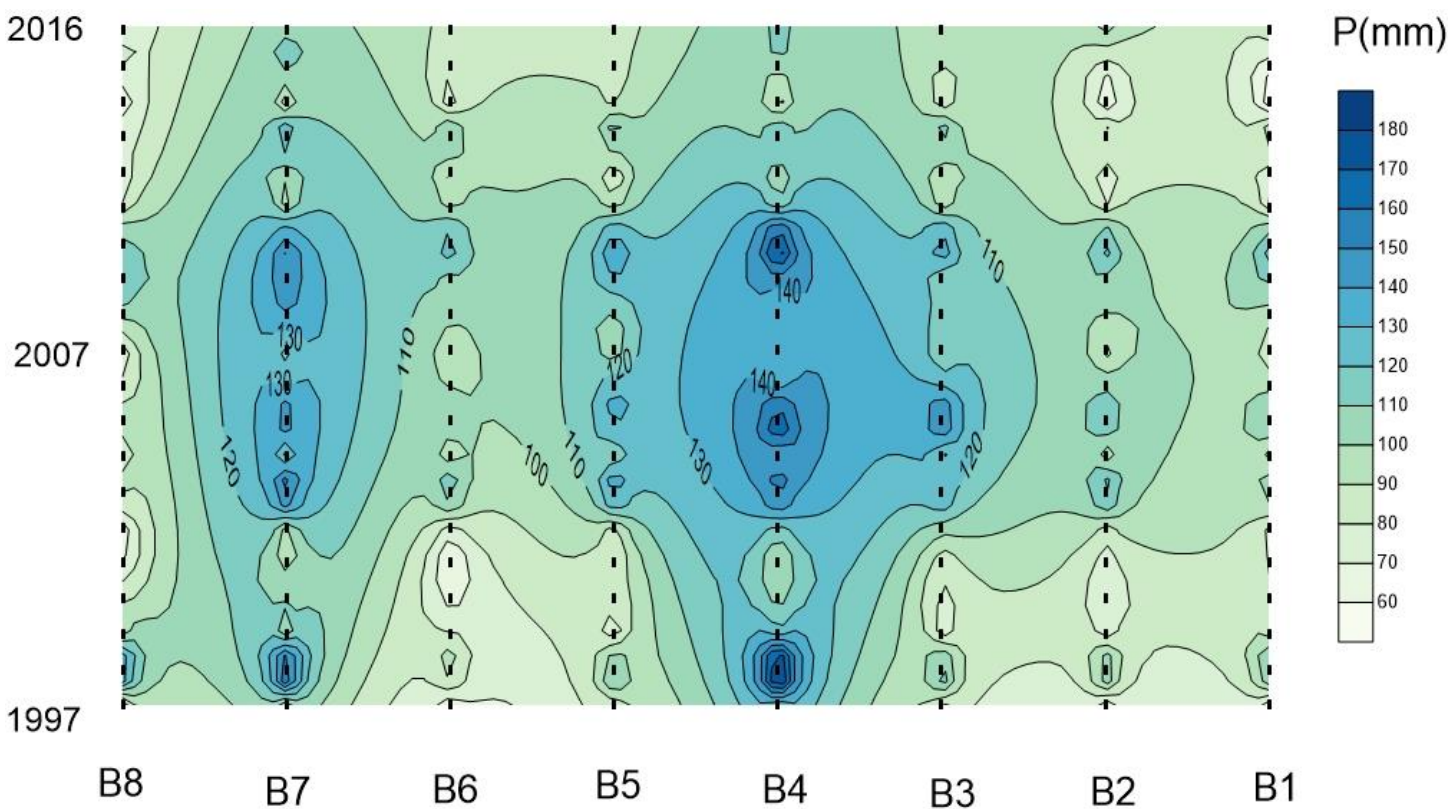

Figura 10. Variação Têmporo-espacial da Pluviosidade -Transect Saúde-Guaratiba. Fonte: Sistema Alerta Rio. Elaborado

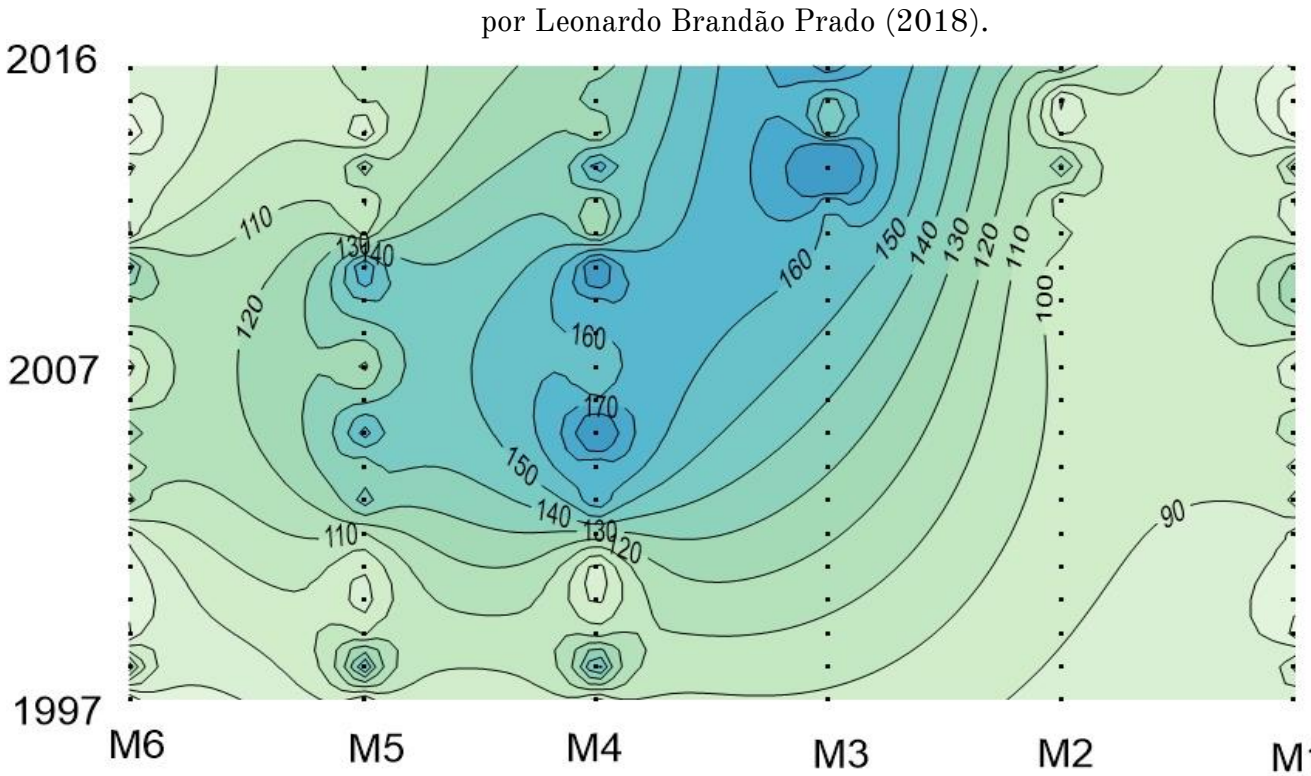

Figura 10. Variação Têmporo-espacial da Pluviosidade -Transect Saúde-Guaratiba. Fonte: Sistema Alerta Rio. Elaborado por Leonardo Brandão Prado (2018).

Forgiarini et al. (2014) observaram a influência do relevo nas chuvas ocorridas em Silveira Martins, centro do Estado do Rio Grande do Sul, porém esta influência está condicionada à predominância do 
avanço das massas de ar polares (direção principal sudoeste-nordeste) em detrimento à invasão de massas de ar subtropicais (direção principal nordeste-sudeste).

No Estado do Rio Grande do Sul não existe um predomínio no movimento das massas de ar, ou seja, ocorre uma variação da direção do vento, o que condiciona a ocorrência do efeito orográfico. Na cidade do Rio de Janeiro as brisas são importantes durante os anos secos ou de veranicos forte, pois transportam a umidade do mar que fica retida em grande parte nas encostas de barlavento. Agora, quando se verifica a distribuição da pluviosidade e se relaciona com a distribuição da infraestrutura básica na cidade do Rio de Janeiro, observa-se que a mesma ainda apresenta grandes desafios.

A Figura 12, elaborada por Chaiblich et al. (2017), demonstra a distribuição espacial da infraestrutura básica em relação aos serviços de abastecimento de água, de esgotamento sanitário e de coleta de lixo e, com base nisso, identifica-se uma fragilidade ambiental maior nos bairros da Zona Oeste. A falta de coleta de lixo se acentua, principalmente, na região de Jacarepaguá. 

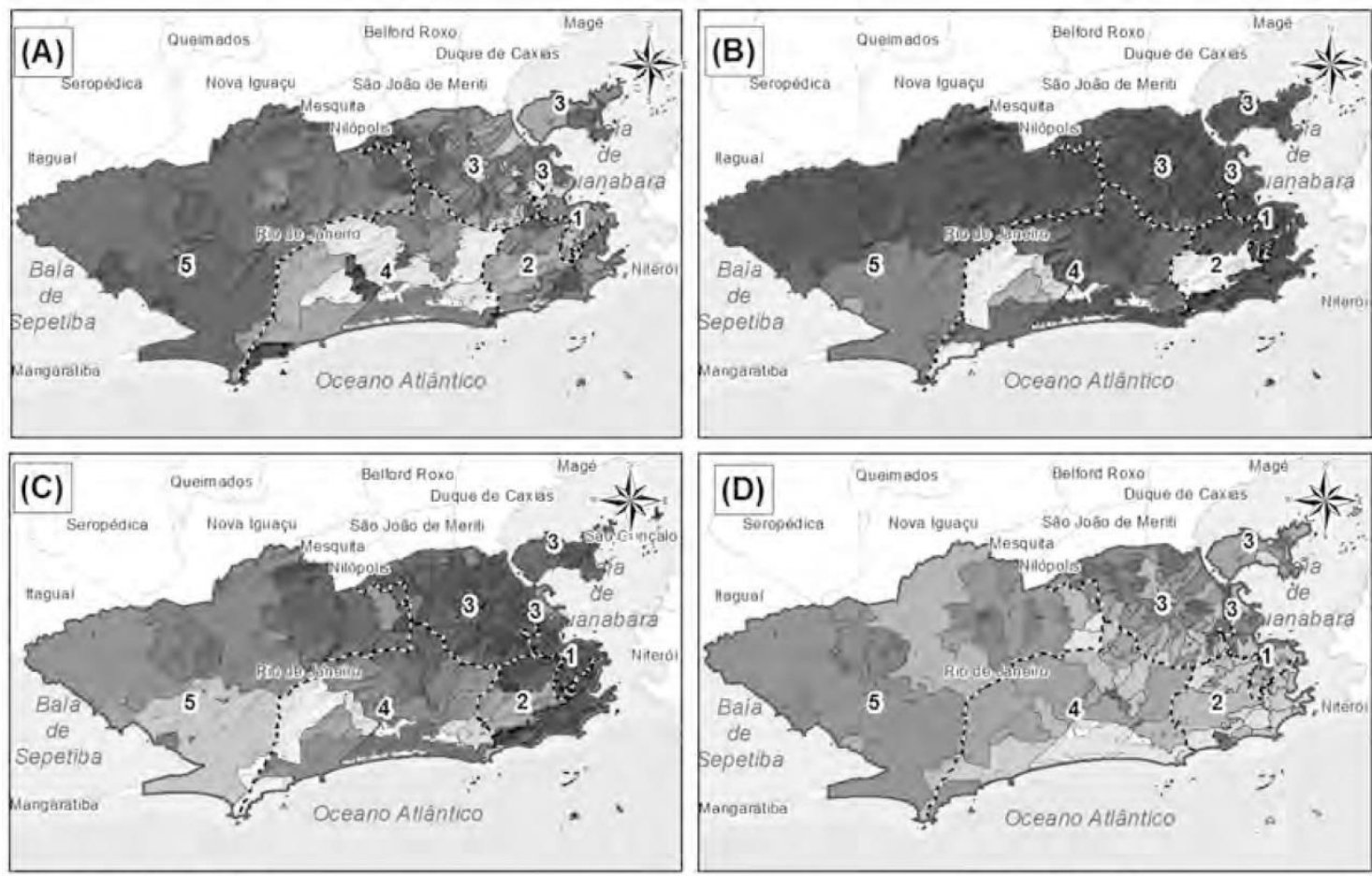

Convençôes Cartográficas

Ligoas Limite dos Bairros Legenda

3 Área de Estudo

(A) Domicilios Particulares Permanentes com Coleta de lixo - público e privado (\%) Niveis

Muito alto: $100 \quad$ Muito baixo: 18

(B) Domicilios Particulares Permanentes com abastecimento de água (\%) Niveis

Muito alto: $100 \quad$ Muito baixo: 9

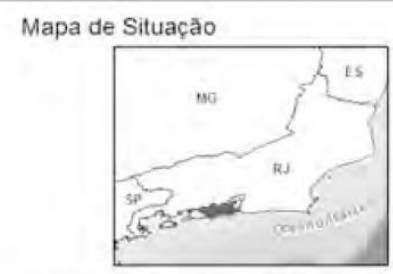

Referências cartogrảicas

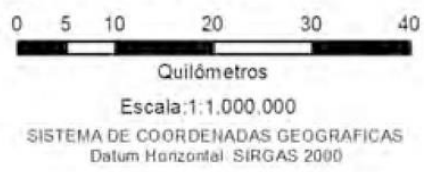

(C) Domicilios Particulares Permanentes com Esgotamento Sanitário (\%) Niveis

Muito alto: $99 \quad$ Muito baixo: 0

(D) Domicilios Particulares Permanente de até 1 salàrio minimo - rendimento mensal per capita (\%) Niveis

Alto Baixo

Figura 12. Distribuição da infraestrutura básica. (A) Domicílios com coleta de lixo; (B) Abastecimento de água; (C) Esgotamento sanitário e (D) Rendimento médio mensal até 1 salário mínimo. Fonte: Chaiblichetal. (2017, p. 233).

Nos bairros da Zona Norte e Centro observa-se também uma debilidade na coleta de lixo. Muitos bairros da cidade possuem áreas geográficas com maior dificuldade para realização da coleta de lixo, levando o poder público a criar estratégias de serviços de coletas por caçambas de lixo, principalmente em áreas de favelas. 
Os bairros da Zona Norte e Centro, apesar dos dados apontarem uma oferta de serviços como abastecimento de água e coleta de esgoto, são áreas que possuem grande número de habitantes vivendo em locais de favela com precariedades habitacionais e dos serviços de infraestrutura sanitária.

Na cidade do Rio de Janeiro os fenômenos naturais, especialmente os climáticos como a precipitação, são inevitáveis, obrigando sempre as comunidades a conviverem com eles. Essa convivência deve ser baseada no conhecimento dos mecanismos e processos geodinâmicos, os quais são submetidos às intervenções da sociedade, mas, para isso, o poder público deve estar à frente do processo de educação ambiental e não apenas do sistema de alerta que, embora importante, ainda é insuficiente para atender às demandas de grande parcela da população da cidade que, em sua maioria, é carente.

\section{CONSIDERAÇÕES FINAIS}

O fenômeno da "sombra de chuva" fica perceptível a sotavento dos Maciços litorâneos onde a formação do relevo possui uma feição que impede a entrada de ventos de sudeste por tratar-se de um imenso anfiteatro, com terraços marinhos e planícies costeiras, circunvizinhas. Porém, o mesmo não ocorre quando da entrada de sistemas frontais de direção sudoeste.

Em relação às áreas mais elevadas, foram registrados os maiores totais pluviais mensais e anuais, porém cabe destacar que os Maciços, ao mesmo tempo em que foram utilizados para segregar socialmente a cidade, o posicionamento dos mesmos concorre para que importantes fatores incidam de maneira distinta, dando origem a domínios ecológicos com características distintas. Se de um lado favorece o surgimento de inúmeras vantagens em termos de beleza cênica, também é responsável pelo surgimento de uma série de problemas urbanos devido às dificuldades de prover infraestrutura básica a uma cidade que é tão espalhada e que ocupa sítios tão diversos e, muitas vezes, acidentados.

A vertente Sul dos maciços litorâneos, por apresentar uma declividade média superior à da vertente Norte, dificulta a sua ocupação, fato esse que não se repetiu na vertente Norte, pois o menor grau de declividade de suas encostas favoreceu o maior adensamento urbano. Consequentemente há uma maior 
ocupação em áreas de risco na vertente Norte. Isso ocorre porque o maior adensamento favorece 0 agravamento de erosão, que alcança maiores dimensões com as chuvas de verão (provenientes de avanços de sistemas frontais) e adquire maior significado à medida que a cidade amplia seu espaço útil de maneira irregular, ampliando os desastres naturais que, ultimamente, são frequentes na sociedade carioca.

Há necessidade de identificar e melhorar as formas de convivência com os eventos pluviais, pois, apesar da cidade do Rio de Janeiro apresentar um Sistema de Alerta, se faz necessário perguntar: 0 que é necessário fazer para alcançar tal nível de convivência?

Talvez seja necessária uma mudança de postura da sociedade, hoje numa posição de vítima nesse contexto, para uma posição proativa nas decisões e/ou negociação de projetos sociais e de destino de ocupação dos espaços urbanos.

\section{AGRADECIMENTOS}

Inicialmente, gostaria de agradecer o convite realizado pelo professor Antônio Carlos da Silva Oscar Júnior e a professora Núbia Beray Armond da UERJ-Campus Maracanã - para participar do 10 Workshop de Climatologia Geográfica do Estado do Rio de Janeiro.E também pela iniciativa de resgatarem os estudos climáticos no Estado do Rio de Janeiro e pelo ensejo de discorrer sobre a temática do clima urbano na UERJ, local que muito me auxiliou no processo de formação profissional, quando estudante de graduação do curso de Geografia da UFRJ, principalmente, nos eventos técnicocientíficos. Agora regressando à UERJ, não mais como ouvinte, mas como um interlocutor de um tema que muito precisa se desenvolver no âmbito da Geografia brasileira. A vocês, o meu MUITO OBRIGADO!!!!

Gostaria ainda de agradecer aos bolsistas do Laboratório de Biogeografia e Climatologia (BIOCLIMA) da Universidade Federal de Viçosa (UFV): Leonardo Brandão do Prado (CNPq) e Márcia Vilela Valdier (Bolsista PIBID), discente do curso de Geografia da UFV. 


\section{REFERÊNCIAS}

ABREU, M. de A. A Cidade, a Montanha e a Floresta. In: ABREU. M. de A. (org.).:Natureza e Sociedade do Rio de Janeiro. Ed. Secretaria Municipal de Cultura, Turismo e Esporte. Rio de Janeiro, p. 54-103, 1992.

AMORIM. F. de; QUELHAS, M. G.; LUIZ, O.; MOTTA, T. S., LUCIA, A. A resiliência das cidades frente a chuvas torrenciais: estudo de caso do plano de contingência da cidade do Rio de Janeiro.Sociedade \& Natureza, Uberlândia, v. 26 , n. 3 , p. 519-534, 2014.

BARRY, R. G. A climatological transect on the eastslope of the Front Range, Colorado. Arctic and Alpine Research, Milan, p. $89-110,1973$.

BEENAERTS, N.; BERGHE, E. V. Comparative study of three transect methods to assess coral cover, richness and diversity. Western Indian Ocean Journal of Marine Scince. Lisboa, v. 4, n. 1, p. 29-37, 2005. Disponível em $<$ https://www.ajol.info/index.php/wiojms/article/view/28471>. Acesso em 9 abr. 2018.

BELIZÁRIO, W. S. Geossistemas e climatologia geográfica: estudos integrados do clima em bacias hidrográficas. Revista Sapiência: Sociedade, saberes e práticas educacionais - UEG/Câmpus de Iporá, v.3, n. 2, p. 2-21 -2014.

BRAAE, E.; DIEDRICH, L.; LEE, G. The travelling transect: Capturing island dynamics, relationships and atmospheres in the water landscapes of the Canaries. Nordic Design Research Conference. Copenhagen-Malmö, n. 5, p. 191-200, 2013. Disponível em < http://www.nordes.org/opj/index.php/n13/article/view/291/273>. Acesso em 10 jul. 2018.

BRANDÃO, A. M. P. M. As alterações climáticas na área metropolitana do Rio de Janeiro: Uma provável influência do crescimento urbano. In: ABREU, M. de A. (org.). Natureza e Sociedade no Rio de Janeiro. Rio de Janeiro: Secretaria Municipal de Cultura, Turismo e Esporte. p. 143-200, 1992.

.Análise Espacial da Pluviosidade no Município do Rio de Janeiro. In:ENCONTRO BRASILEIRO DE CIÊNCIAS AMBIENTAIS, 1, Rio de Janeiro. Anais..., Rio de Janeiro, BNDES, p. 250-267,1994.

O clima urbano da cidade do Rio de Janeiro. 362f. Tese (Doutorado em Geografia Física), Faculdade de Filosofia, Letras e Ciências Humanas, Programa de Pós-graduação em Geografia Física, USP, 1996.

A chuva e a ação humana: Uma infeliz coincidência. In: ROSA, L. P.; LACERDA, W. A. (orgs.). Tormentas Cariocas: Seminário de Prevenção e controle dos Efeitos dos Temporais no Rio de Janeiro. Rio de Janeiro: COPPE/UFRJ. p. 21-38. 1997.

. Clima urbano e enchentes na cidade do Rio de Janeiro. In: GUERRA, A. J.; CUNHA, S. B. (orgs.). Impactos ambientais urbanos no Brasil. Rio de Janeiro: Bertrand Brasil. p. 47-109, 2001.

BROWER, J. E. \& ZAR, J. H. Field andlaboratorymethods for general ecology. 2 ed. Wm. C. Brown Publishers, Dubuque, Iowa, 1984, 226p.

BRUNO, L. La forêtaucœur de laville. Géographieetcultures, Paris, n. 62, p. 1-15, 2008. Disponível em: http://ge.revues.org/2311. Acesso em: 24 jun. 2018.

BUCKLAND, S. T.; TURNOCK, B. Robustline transect method. Biometrics, London, v. 48, n. 3, p. 901-909, 1992. Disponível em: <http://www.jstor.org/stable/2532356>. Acesso em 10 abr. 2018.

CAMBREZY, L.; MAXIMY, R. La cartographieendébat: Représenter ou convaincre. Paris: Karthala: Orstom, 199p. Disponível em http://horizon.documentation.ird.fr/exl-doc/pleins_textes/pleins_textes_7/b_fdi_03_04/42938.pdf. Acesso em 16 jul. 2018. 
CÂNDIDO, D. H.; NUNES L. H. Influência da Orografia na Precipitação da Área Entre o Vale do Rio Tietê e a Serra da Mantiqueira. Revista GEOUSP- Espaço e Tempo, São Paulo, v. 24, n. 24, p. 8-27, 2008.

CALDARELLI, S. Levantamento arqueológico em planejamento ambiental. In: FUNARI, P. P. A.; NEVES, E. G.; PODGORNY, I. (Org.). REUNIÃo INTERNACIONAL DE TEORIA ARQUEOLÓGICA NA AMÉRICA DO SUL, 1. Anais... São Paulo: MAE-USP, p. 347-370, 1999.

CAVALCANTI, L. C. S. Da descrição de áreas à teoria dos geossitemas: Uma abordagem epistemológica sobre sínteses naturalistas. 216f. Tese (Doutorado em Geografia). Centro de Filosofia e Ciências Humanas, Programa de Pós-graduação em Geografia. Universidade Federal de Pernambuco. 2013.

CARDoso, D. J.; VIBRAnS, A. C.; REZENDE, A. V.; PAREYN, F. C.; FREITAS, J. V.; ROsOT, M. A. D.; OLIVEIRA, Y. M. M. Determinação do comprimento ótimo de transectos para estimativa de necromassa florestal. Pesquisa Florestal Brasileira (PFB), Colombo, v. 33, n. 75, p. 317-325, 2013.

CHAIBLICH, J. V.; LIMA, M. L. S.; OLIVEIRA, R. F.; MONKEN, M.; PENNA, M. L. F. Estudo espacial de riscos à leptospirose no município do Rio de Janeiro (RJ). Saúde Debate, Rio de Janeiro, v. 41, n. Especial, p. 225-240, 2017.

CHIG, I. A.; COUTO, E. G.; NOVAES FILHO, J. P.; RODRIGUES, L. C. M.; JOHNSON, M. S.; WEBER, O. L. S. Distribuição espacial da granulometria, cor e carbono orgânico do solo ao longo de um transect em microbacias na Amazônia meridional. Acta Amazonica, Manaus, v. 38, n. 4, p. 715-722, 2008.

CONTI, J. B. Climatologia e Geografia. Revista Geousp. São Paulo, n. 9, p. 91-94, 2001.

CUNHA, S. B; FREITAS, M.W.D. Geossistemas e Gestão Ambiental na Bacia Hidrográfica do Rio São João-RJ. GEOgraphia, Niterói, v. 6, n. 12, p. 87-110, 2004.

DAVEGNA, D. C.; FIALHO, E. S. Os impactos pluviais na área da micro bacia de São Conrado-RJ (1996-2001). in: SENISA, 1.2002. Paraná, Anais..., Curitiba: UFPR, 2002. Cd-room.

DERECZYNSKI, C. P; OLIVEIRA, J. S; MACHADO, C. O. Climatologia da precipitação no município do Rio de Janeiro. Revista brasileira de Meteorologia. São Paulo, v.24, n.1, p. 24-38, 2009.

DIEDRICH, L.; GINI, L.; BRAAE, E. The transect as a method for mapping and narrating water landscapes: Humboldt's open works and transareal travelling. New American Notes Online, Bind 6, 2014. Disponível em

<http://www.nanocrit.com/issues/6-2014/transect-method-mapping-narrating-water-landscapes-humboldts-open-workstransareal-travelling $>$. Acesso em 19 Jun. 2017.

DIAS, H. C. T.; SCHAEFER C. E. G. R.; FERNANDES FILHO; OLIVEIRA E. I.; A. P; MICHEL, R. F. M.; LEMOS JR.J. B. Caracterização de solos altimontanos em dois transects no parque estadual do Ibitipoca (MG). Revista Brasileira de Ciência do Solo, Viçosa-MG, v. 27, p.469-481, 2003.

EGERTON, F. N. HistoryofEcologicalSciences, Part 61A: Terrestrial Biogeography and Paleobiogeography, 1700-1830s. Bulletin of the Ecological Society of America, New York, v. 99, n. 2, p. 192-241, 2018.

ELY, D. F. Teoria e Método da Climatologia Geográfica Brasileira: Uma abordagem sobre seus discursos e práticas. $208 f$. Tese (Doutorado em Geografia), Universidade Estadual Paulista, Faculdade de Ciências e Tecnologia, Presidente Prudente, UEP/FCT, São Paulo, 2006.

FERREIRA, V. O. A abordagem da paisagem no âmbito dos estudos ambientais integrados.GeoTextos, Salvador, v. 6, n. 2, p. 187-208, 2010. 
FIALHO, E. S.; AMORIM, M.; BRANDÃO, A. M. P. M.Um Estudo Comparativo dos Impactos Pluviométricos causados na Bacia do Rio Cachoeira e do Rio Maracanã no período de 1990-1996.Boletim Climatológico. - UNESP. Presidente Prudente-SP, v. 2, n.3, p. 145-150 1997.

FIALHO, E. S.; BRANDÃO, A. M. P. M.As chuvas e a (des)organização do espaço urbano na cidade do Rio de Janeiro. . In:SIMPOSIO BRASILEIRO DE GEOGRAFIA FISICA APLICADA, 7, Curitiba. Anais...,Paraná, UFPR, cd-room, 1997.

FIALHO, E. S.As Chuvas e a (Des) Organização do Espaço Urbano Carioca. Dissertação (Monografia em Geografia). CCMN-IGEO, Rio de Janeiro, 1998, 60p.

FIALHO, E. S., BRANDÃO, A. M. P. M. As Chuvas e a (Des) organização do Espaço Urbano Carioca. Revista Geouerj. Rio de Janeiro, v. 4, n. 8, p. 39-53, 2000.

FONSECA, F. P. O potencial analógico da cartografia. Boletim Paulista de Geografia, São Paulo, n. 87, p. 85-110, 2007. Disponível: < http://www2.fct.unesp.br/docentes/geo/raul/cartografia_tematica/leitura\%201/fernanda.pdf $>$. Acesso em 19 Jun. 2017.

FORGIARINI, R.; VENDRUSCULO, D. S.; RIZZI, E. S. Análise de chuvas orográficas no centro do estado do Rio Grande do Sul. Ciência e Natura, Santa Maria-RS, v. 36,n. 2,p. 193-200, 2014.

GALVÃO, M.C.C. Focos sobre a Questão Ambiental no Rio de Janeiro.in: ABREU, M. A. (org).: Sociedade e Natureza do Rio de Janeiro. Prefeitura do Rio de Janeiro. Rio de Janeiro, p. 13-26, 1992.

HEYD, T. Alexander von Humboldt y launidad de la naturaliza. Revista International de EstudiosHumboldtianos. Berlin, v. 18, n. 35, p. 25-37. 2017. Disponível em <http://www.hin-online.de/index.php/hin/article/view/260/474 >. Acesso em 12 jun. 2018.

JOURET, B. La méthodedutransectappliquée à l'analyseurbaine. Un exemple bruxellois. Revue de géographie de Lyon, Lyon, v. 47, n.1, p. 77-96, 1972. Disponível em: <http://www.persee.fr/doc/geoca_0035-113x_1972_num_47_1_1602>. Acesso em 4 abr. 2018.

LÉVI-STRAUSS, C. Tristes Trópicos. Tradução NoeliaBastard. Barcelona, EdicionesPaidós Ibérica, 1988, 468p. Disponível em: < https://ia802700.us.archive.org/12/items/pdfy-39SHtG9K3mnxpI_w/Tristes\%20Tropicos\%20\%20Levi-Strauss.pdf $>$. Acesso em 1 ago. 2018.

MEHARZI, M. K. Le rôle de l'orographiedanslarépartitionspatialedesprécipitationsdanslemassif de l'Aurès. Méditerranée, Paris, v. 80, n. 3-4, p. 73-78, 1994. Disponível em: < http://www.persee.fr/doc/medit_0025-

8296_1994_num_80_3_2861>. Acesso em 2 abr. 2018.

MILANESI, M.A. Avaliação do efeito orográfico na pluviometria de vertentes opostas da Ilha de São Sebastião (IlhaBelaSP). 2007. 150f. Dissertação (mestrado em Geografia Física). USP/FFLCH/DG, São Paulo, 2007.

MONTEIRO, C. A. F. Derivações antropogênicas dos geossistemas terrestres no Brasil e alterações climáticas: perspectivas urbanas e agrárias ao problema da elaboração de modelos de avaliação. In: SIMPósIo SOBRE A UNIDADE BIOLÓGICA, TURíSTICA E ECONÔMICA. São Paulo, p. 43-74 (Academia Brasileira de Ciências, Publicação 14), 1978.

MONTEIRO C. A. de F. Adentrar a cidade para tomar-lhe a temperatura. RevistaGeosul, Florianópolis, v. 5, n. 9, p. 61-79, 1990.

MONTEIRO, C. A. F. Geossistemas: A História de uma Procura. São Paulo, Contexto, 2000. 127p. 
MONTEIRO, C. A. F. Os Geossistemas como Elemento de Integração na síntese Geográfica e Fator de Promoção Interdisciplinar na Compreensão do ambiente. Revista de Ciências Humanas. Florianópolis-SC, v. 14, n. 19, p. 67-101, 1996.

NASCIMENTO, F. R.; SAMPAIO, J. L. F. Geografia Física, Geossistemas e Estudos integrados da paisagem. Revista da Casa da Geografia de Sobral. Sobral-CE, v. 6/7, n. 1, p. 167-179, 2004-2005.

NEVES, C. E. Geossistema: a História de uma Pesquisa -: Trajetórias e Tendências no Estado de São Paulo. $191 \mathrm{f}$. (Dissertação de Mestrado em Geografia), Departamento de Geociências da Universidade Estadual de Londrina, Paraná, 2015.

NIMER, E. Climatologia do Brasil. Instituto Brasileiro de Geografia e Estatística, Rio de Janeiro, RJ, 1989.

OLIVEIRA, A. Interações entre sistemas frontais na América do Sul e a convecção daAmazônia. Dissertação (Mestrado em meteorologia) - Instituto Nacional de Pesquisas Espaciais. São José dos Campos: Instituto Nacional de Pesquisas Espaciais, 1986 .

OLIVEIRA, C. S.; NEVES, C. E. Aspectos do pensamento geossistêmico na Rússia, França e Brasil: Estudos de sociedade(s) e natureza(s) distintas? Revista de Geografia. Juiz de Fora-MG, v.6, n.4, p.315-328, 2016.

OLIVEIRA JÚNIOR, J.F.; SOUZA, J.C.S.; DIAS, F. O.;GOIS, G.;GONCALVES, I. F. S.; SILVA, M.S. Caracterização do Regime de Vento no Município de Seropédica, Rio de Janeiro (2001-2010). Floresta e Ambiente, Seropédica-RJ, v.20, n.4, p. 447-459, 2013.

PALMA, A., FIGUERA, R.; VÍCTOR; Rui, H. Evaluacion de ribera y habitat fluvial a traves de losindicesQBReIHF. Gayana, Concepcion-Chile, v. 73, n. 1, p. 57-63, 2009.

PIMENTEL, L. C. G.'MARTON, E.; SILVA, M. S.; JOURDAN, P. Caracterização do regime de vento em superfície na Região Metropolitana do Rio de Janeiro. Revista de Engenharia Sanitária Ambiental, Rio de Janeiro, v. 19, n. 2, p. 121$132,2014$.

POUSIN, F., MARCO, A.; BERTAUDIERE-MONTES; BARTHELEMY, C.; TIXIER, N.Le transect: outil de dialogue interdisciplinaire et de médiation. Vertigo: La revueélectroniqueensciences de l'environnement. Hors-série,24, Jun. 2016. Disponível em: <http://vertigo.revues.org/17372>. Acesso em 10 Jun. 2016.

ROBIC, M. C. Transect. Hypergéo. Paris, 2014 Paris.Disponível em: $<$ http://www.hypergeo.eu/spip.php?article60 > Acesso em 10 jul. 2018.

ROCHA, V. M.; FIALHO, E. S. Uso da terra e suas implicações na variação termo-higrométrica ao longo de um transeto campo-cidade no município de Viçosa-MG. Revista de Ciências Humanas. Revista de Ciências Humanas, Viçosa-MG, v. 10, n. 1, p. 64-77, 2010.

RODRIGUES, C. A teoria geossistêmica e sua contribuição aos estudos geográficos e ambientais. Revista do Departamento de Geografia, São Paulo, n.14, p. 69-77, 2001.

SANT'ANNA NETO, J. L.O clima urbano como construção social: Da vulnerabilidade polissêmica das cidades enfermas ao sofisma utópico das cidades saudáveis. Revista Brasileira de Climatologia, Curitiba, Ano 7, v. 8, p. 45-60, 2011.

SANTOS, H. S.; FLEXOR, J. M. Estudo da bacia dos parecis a partir da integração de dados gravimétricos, magnetométricos e magnetotelúricos. Geociências, São Paulo, UNESP, v. 32, n.3, p.411-428, 2013.

TIXIER, N. Le transecturbain. Pour une écriturecorréléedesambianceset de l'environnement. In: BARLES, S.; BLANC, N. (orgs.).:Écologiesurbaines. Surleterrain. Paris, Ed. Economica-Anthropos-PIRVE; p. 130-148, 2016, Disponível em < https://hal.archives-ouvertes.fr/hal-01518091>. Acesso em 10 abr. 2018. 
TIXIER, N. Transectos urbanos y relatos de lugar. In: PUCHADES, W. G.; MIGUEL, M. (orgs.).:La cultura de locomúnPrácticascolectivasdelsiglo XXI. p. 25-38, 2016, 171p. Editorial UniversitatPolitècnica de Valência. Disponível em<https://riunet.upv.es/handle/10251/79493>. Acesso em 10 abr. 2018.

TROPPMAIR, H. Geossitema. Revista Mercator, Fortaleza, v. 5, n. 10, p. 79-88, 2006.

UGEDA JUNIOR, J. C.; AMORIM, M. C. C. Reflexões acerca do sistema clima urbano e sua aplicabilidade: pressupostos teórico-metodológicos e inovações técnicas. Revista do Departamento de Geografia, São Paulo, volume especial, p.160-173, 2016.

VETTER, D. M. A segregação residencial da PEA na região metropolitana do Rio de Janeiro, segundo grupos de rendimento mensal. Revista Brasileira de Geografia, Rio de Janeiro, n. 43, 16p. 1981.

WULF. A. A invenção da natureza: A vida e as descobertas de Alexander vonHumbolt. Tradução: Renato Marques. 1 ed. São Paulo: Planeta, 216. 587p.

YAPP, W. B. The TheoryofLineTransects, BirdStudy, London, v. 3, n. 2, p. 93-104, 1956. Disponível em: $<$ https://doi.org/10.1080/00063655609475840>. Acesso em 3 abr. 2018.

WALTER, H. Vegetação e Zonas Climáticas. São Paulo, E.P.U, 1986. 330p.

SOTCHAVAV. B. 0 estudo de geossistemas. Instituto de Geografia. Universidade de São Paulo. São Paulo: Ed. Lunar, 1977.

ZAVATtini, J. A. O paradigma da Análise Rítmica e a Climatologia Geográfica Brasileira. Geografia, Rio Claro, v. 25 , p. $25-43,2000$.

; BOIN, M. N. Climatologia Geográfica: teoria e prática de pesquisa. Campinas, São Paulo, Ed. Alínea, 2013. 152p. 